\title{
Teratogenic effects of polar compounds in oxidized frying oil
}

Authors:

Yu-Shun Lin

Pei-Min Chao*

Department of Nutrition,

China Medical University,

Taichung 404, Taiwan

*Corresponding author:

Dr. Pei-Min Chao

Institute of Nutrition, China

Medical University,

Taichung 404, Taiwan

Email:

pmchao@mail.cmu.edu.tw

Tel: +(886)-4-22053366,

ext. 7509

Fax: +(886)-4-22062891

\begin{abstract}
Although deep-fried foods are very popular, the safety of oxidized frying oil (OFO), which is ingested with fried food, is a concern. Consequently, food safety regulations in many countries set an upper limit of $25 \%$ polar compounds (PC). The PC comprise all oxidatively altered components in used oils; they may be regarded as a xenobiotic or endocrine-disrupting chemical, as they activate PPAR $\alpha$ and induce expression of detoxifying cytochrome P450 monoxygenase and phase II conjugation enzymes to facilitate their own catabolism. Recently, we reported that pregnant C57BL/6J mice fed PC had a higher incidence of fetuses with congenital malformations. This review summarizes the chemical reactions and PC composition in OFO, effects of PC on modulating transcriptional activity of xenobiotic receptors including aryl hydrocarbon receptor, constitutive androstane receptor, pregnane $X$ receptor and PPAR $\alpha$, the importance of retinoic acid (RA) in organogenesis of developing embryos, as well as teratogenic effects of PC. Plausible underlying mechanisms are also discussed. We speculate that the pathogenesis of congenital malformations is disturbed RA metabolism via crosstalks between xenobiotic receptors.
\end{abstract}

Keywords: oxidized frying oil, polar compounds, teratogenesis, retinoic acid, cytochrome P450 


\section{Introduction}

Due to their crispness and aromatic properties, deep-fried foods are immensely popular worldwide. However, the safety of oxidized frying oil (OFO), which is estimated to comprise $10-40 \%$ of fried food (Moreira et al. 1991), is always a concern. Under normal cooking practices, OFO is regarded as safe, due to induction of detoxifying cytochrome P450 enzymes and limited absorption of toxic polymers produced during the deep-frying process (Huang et al. 1988, Gonz'alez-Munoz et al. 1998). However, in addition to increased morbidity of cardiovascular diseases associated with oxidative stress (Cohn 2002, Kanner 2007) or cancers ascribed to some potential carcinogens (Tareke et al. 2002, Wenzl et al. 2006, Shoeb et al. 2014), there are important nutritional and metabolic impacts of OFO. Dietary OFO reduced TG and cholesterol concentrations through modulations of PPAR $\alpha$, SREBP-1c and SREBP-2 activity (Chao et al. 2001, Sulzle et al. 2004, Koch et al. 2007). Nevertheless, hypolipidemic benefits for protection against cardiovascular disease might be compromised by excess production of reactive oxygen species. In addition, rodents fed a diet containing 20\% OFO had glucose intolerance and insulin deficiency (Chao et al. 2007, Liao et al. 2008), due to oxidative stress-associated $\beta$-cell dysfunction (overcome with $\alpha$-tocopherol supplementation) (Chiang et al. 2011). In addition, OFO-induced cytochrome P450-detoxifying enzymes have been implicated in increased catabolism of vitamin E (Liu \& Huang 1996, Birringer et al. 2001) and probably vitamin A (Tang \& Huang 1998). We recently reported that dietary OFO increase teratogenicity, with polar compounds (PC) in the OFO is the underlying cause (Huang et al. 2014). We speculated this phenomenon was due to a disturbance of retinoic acid (RA) metabolism, via modulation of activities of xenobiotic receptors by OFO (specifically PC). This review summarizes chemical reactions in OFO, the composition of PC, OFO (or PC) effects on xenobiotic receptors, PC-mediated teratogenesis, and plausible underlying mechanisms. Potential risks of PC on other reproductive outcomes (e.g. endocrine disturbance) are also discussed. These issues highlighted the importance of the safety of used oil, particularly for pregnant women. 


\section{2. $\mathrm{PC}$ in $\mathrm{OFO}$}

Oil contributes to food texture and flavor. Composition of oil changes due to new compounds generated and released from foods, alteration of TG components in oil, as well as degradation of lipid soluble nutrients originally present in oil.

\subsection{Chemical reactions and} products in OFO

Deep-fat frying involves a complex interaction among foods, water, air and oil under high temperature. Typical frying temperatures $\left(\sim 130-220^{\circ} \mathrm{C}\right)$ cause many chemical reactions, including hydrolysis, oxidation, polymerization, isomerization, cyclization, and fission (Choe \& Min 2007). Hydrolytic products from oil accelerate oxidative deterioration, although their concentrations in used oil are lower than those of TG polymers (dimers plus oligomers) and monomers (Dobarganes \& Ma'rquez-Ruiz 2007). Thermal oxidation is similar to autoxidation (involves chain reactions of free radicals) but the oxidation rate is much greater at high temperatures. Furthermore, with more unsaturated fats, more free radicals are generated. Initiation, propagation, and termination of free radicals in thermal oxidation of oil have been well documented (Choe \& Min 2007).

Lipid peroxides, the primary oxidation products, are rapidly degraded or dispelled under high temperatures. Frying oil prepared by simulating realistic cooking practice usually yields POV 5-30 $\mathrm{meq} / \mathrm{kg}$ oil, in contrast to some toxicity studies applying oil with POV $\geq 100$ $\mathrm{meq} / \mathrm{kg}$, which was prepared by pumping air into oil at room temperature, with the product being organoleptically unacceptable (Nawar 1984). Fission of hydroperoxides produces aldehyde, ketone and oxoacid, which might be volatile (due to their low molecular weight) or retained in oil if they are attached to a TG. Oxidation products such as hydroxy octadecadienoic acid, 4-hydroxy-2-nonenal and malondialdehyde frequently investigated for toxicity (Chow 2007) are believed to be produced endogenously under oxidative stress, or directly from OFO ingestion after lipase digestion. The carcinogens acrolein and polycyclic aromatic hydrocarbons are present in smoke and their health concerns are related to inhalation rather than ingestion (Gao et al. 1987, Chen \& Chen 2003, 
Stevens \& Maier 2008). Acrylamide, another highly suspected carcinogen, is present in deep-fried starchy foods, but its release into oil is negligible (Totani et al. 2007).

Of great nutritional concerns in used oil are non-volatile secondary oxidation products, mainly oxidized TG monomers, dimers and polymers, because they are absorbed into fried foods. The oxidized TG contains at least one oxygenated group in esterified fatty acids (potentially a mixture of hydroperoxy, hydroxy, epoxy, and keto, as well as polyoxygenated compounds). The dimers and polymers are complex structures in which TG monomers are covalently linked through $\mathrm{C}-\mathrm{C}$ or $\mathrm{C}-\mathrm{O}-\mathrm{C}$ bonds (Dobarganes \& Ma'rquez-Ruiz 2015). Compared to the parent non-modified $\mathrm{TG}$ in fresh oil, polarity increased proportionate to deterioration of OFO, due to accumulation of these oxygenated compounds (i.e. PC). Formation of PC is affected by many factors, including heating temperature, duration of cooking, source of oils, antioxidants, heating methods (continuous or discontinuous), foods, and type of fryer. In vivo, oxidized TG monomers are extensively hydrolyzed and highly absorbable, as dietary hydroxyl- and epoxy- fatty acids incorporated in lipoproteins were detected in humans using labeled fatty acid approaches (Wilson et al. 2002a, 2002b). In addition, TG dimers and oligomers are also absorbable, though with a lower hydrolysis rate (11-42\%) (Ma'rquez-Ruiz et al. 1998).

\subsection{Nutrients changes in $\mathrm{OFO}$}

Vegetable oils are rich in vitamin E, but it is depleted following deep-fat frying. Frying potatoes in a mixture of soybean and rapeseed oil at $180^{\circ} \mathrm{C}$ caused greater degradation of $\gamma$-tocopherol than $\alpha$ - and $\beta$-tocopherol (Miyagawa et al. 1991). However, for potatoes fried in soybean oil at $205^{\circ} \mathrm{C}, \alpha$-tocopherol was the most vulnerable, with nearly complete destruction after $24 \mathrm{~h}$ of discontinuous frying (Liu \& Huang 1995).

Oxidation reduced concentrations of essential fatty acids. For example, linoleic acid and linolenic acid comprise approximately 55 and $8 \%$ of total fatty acids, respectively in fresh soybean oil. However, after intermittent frying at $205^{\circ} \mathrm{C}$ for $24 \mathrm{~h}$, they were reduced by 20 and 50\% (Chao et al. 2001).

\subsection{Quality evaluation for used oil}


Indicators commonly used to evaluate the quality of used oil include acid value (AV; to quantify free fatty acids), conjugated diene value $\left(\mathrm{OD}_{233}\right.$; conjugated fatty acids), peroxide value (POV; hydroperoxides), thiobarbituric acid value (malondialdehyde), carbonyl value (COV; compounds with a carbonyl group, e.g. aldehyde or ketone), active oxygen method (oil stability), decreases in iodine values and smoking point, increases in foaming and viscosity, as well as total PC. Tracking one specific compound usually does not assess oil quality, as formation and degradation of various products occur simultaneously. However, total PC (based on adsorption chromatography; Standard IUPAC Method 2.507) globally measures altered components, instead of one particular compound. According to A.O.C.S. standard (adopted by many countries), oil for human consumption should not have total PC concentrations exceeding $25 \%$ of oil weight (Firestone 2007). However, in a survey of food in restaurants and fast food outlets across Europe, PC ranged from 7.5-61.4\% (Saguy \& Dana 2003, Marmesat et al. 2007). Therefore, food prepared in fast food outlets where discontinuous frying is common
(Dobarganes \& Ma'rquez-Ruiz 2015), should be carefully monitored.

\section{Xenobiotic-mimic effects of PC}

Dietary OFO or PC can be regarded xenobiotic as it is foreign to the body, lipophilic, and capable of inducing expression of cytochrome P450 detoxifying enzymes to facilitate its own catabolism (Huang et al. 1988). Accordingly, OFO or PC may conceal some health risks via modulating xenobiotic receptor activities, such as aryl hydrocarbon receptor (AhR), constitutive androstane receptor (CAR), pregnane $\mathrm{X}$ receptor (PXR), and PPAR $\alpha$.

\subsection{AhR, CAR and PXR}

In 1960s, based on 600 publications using OFO prepared under realistic cooking conditions, Artman concluded that consumption of $\mathrm{OFO}$ by rodents caused no apparent histological pathology, although there was growth retardation, liver enlargement and oxidative stress (Artman et al. 1969). Later, Huang et al. (1988) reported that hepatic activities of aminopyrine $\mathrm{N}$-demethylase, analine hydroxylase, NADPH-cytochrome c reductase, UDP-glucuronyl transferase, GSH S-transferase, as well as cytochrome P450 content were significantly increased 
in rats fed a diet containing deteriorated soybean frying oil. That this OFO-induced cytochrome P450 monoxygenase and phase II conjugation enzymes convert OFO into more polar derivatives for excretion, provided an explanation for the apparent lack of toxicity. The cytochrome P450 enzymes constitute a superfamily of haem-thiolate enzymes which are ubiquitous in nature and participate in various aspects of metabolism, including detoxification of xenobiotics, catabolism of fatty acids and lipid soluble vitamins, and steroidogenesis (Nebert \& Russell 2002).

Though there are reports of cytochrome P450 induction by acrylamide and polycyclic aromatic hydrocarbons (Ghanayem et al. 2005, Bansal et al. 2014), induction of cytochrome P450 by PC or its working mechanisms remains unknown. Transcription factors AhR, PXR, and CAR are well-recognized xenobiotic sensors and when activated, can induce expression of a largely overlapping array of target genes encoding phase I and II enzymes (Tolson \& Wang 2010). In contrast to AhR and CAR can be activated in ligand-dependent or independent manner, PXR activation is dependent exclusively on ligand binding, as a bulky and flexible ligand-binding cavity enables it to accommodate structurally diverse ligands (Ekins et al. 2009).

Based on their mRNA levels, Cyp1a1, Cyp3a11 and Cyp2b10, serve as target genes controlled by AhR, CAR and PXR respectively. We reported that the transcriptional activity of AhR was down regulated, whereas CAR and PXR were up regulated by PC in the liver of pregnant C57BL/6J mice fed a diet with $10 \%$ PC (Lin et al. manuscript in review). Consistent with these in vivo data, an in vitro reporter assay also confirmed that transactivity of AhR was inhibited by hydrolyzed fatty acids from PC (Huang et al. 2014). These results evidenced that PC modulated activity of AhR, PXR and CAR.

\subsection{PPAR $\alpha$}

Based on similarities between responses elicited by dietary OFO and peroxisome proliferators (PP), i.e. hepatomegaly, reduced liver $\mathrm{TG}$, and induction of cytochrome P450, we (Chao et al. 2001) and Sulzl et al. (2004) demonstrated that dietary OFO contained PPAR $\alpha$ activators. It is well established that PPAR belongs to a superfamily of 
steroid hormone receptors with a common structure, including a DNA-binding domain and a ligand-binding domain (Issemann \& Green 1990). In addition to PP, fatty acids and eicosanoids are endogenous PPAR ligands (Desvergne \& Wahli 1999). Upon activation by ligands, PPAR heterodimerizes with retinoid-X receptor (RXR) and promotes transcription of its target genes by binding to a peroxisome proliferator responsive element. Target genes of PPAR $\alpha$ are mainly a homogeneous group of genes that participate in various aspects of lipid catabolism such as fatty acid uptake and binding, fatty acid oxidation (in microsomes, peroxisomes and mitochondria), ketogenesis, and lipoprotein assembly and transport (Desvergne \& Wahli 1999). Although frequent consumption of frying oil is linked with obesity and an increased risk of cardiovascular diseases, when the comparison was made at equal dietary fat levels, there were consistently reductions in blood TG concentrations, and liver and body fat content of animals fed OFO compared to those fed fresh oil (Eder 1999, Lu \& Lo 1995, Chao et al. 2001, Chao et al. 2007).
Based on a reporter assay, the PPAR $\alpha$ activating effect of OFO was attributed to PC (Huang et al. 2014). Cyclic fatty acid monomer is a PPAR $\alpha$ activator (Martin et al. 2000), although it is present at relatively low concentrations (0.01-0.7\%) in OFO (Romero et al. 2006). In our unpublished data, sequential fractionation of PC led to identification of hydroxyl-fatty acids as a PPAR $\alpha$ activator. In addition, hydroxy or hydroperoxy fatty acids, e.g. 9- or 13- hydroxy octadecadienoic acid and 13-hydroperoxy octadecadienoic acid, were also reported to be PPAR $\alpha$ activators in cell culture models (Nagy et al. 1998, Delerive et al. 2000).

\subsection{Nutritional concerns for}

\section{xenobiotics}

That xenobiotics disturbed metabolism of vitamins $\mathrm{E}$ and $\mathrm{A}$ was apparent in a study where concentrations of $\alpha$-carboxyethyl hydroxychroman and RA were modulated by administration of CYP inhibitors or activators in hepatocytes (Birringer et al. 2001, Parker et al. 2000, Van Wauwe et al. 1990). In vivo, $\alpha$-tocopherol was metabolized into $\alpha$-carboxyethyl hydroxychroman for urinary excretion by CYP3A-directed 
$\omega$-oxidation and peroxisomal $\beta$-oxidation (Birringer et al. 2001). Dietary OFO enhanced CYP3A and $\beta$-oxidation. Thus, more than oxidative stress, OFO might further accelerate depletion of $\alpha$-tocopherol through increased catabolism and excretion (Liu \& Huang 1996, Huang et al. 2009). Regarding vitamin A, adult male rats fed OFO had decreased vitamin A concentrations in liver and plasma, although the mechanism was not determined (Tang \& Huang 1998).

\section{Teratogenic effects of PC}

In our two-generation study, pups from dams fed OFO during pregnancy had higher perinatal mortality, due to dystocia and cannibalism of offspring; furthermore, there was an increased incidence of congenital malformations (Huang et al. 2014). This was not attributed to vitamin E deficiency, since supplementation of the diet of OFO-fed mice with tocopheryl acetate failed to prevent this problem, even though tissue vitamin $\mathrm{E}$ status was restored (Huang et al. 2014).

\subsection{Vitamin $A$ and embryonic} development

Twenty years ago, ecologists recognized that retinoids were involved in malformations in vertebrates and invertebrates induced by environmental pollutants and that blood retinoid concentrations were a sensitive biomarker for pollutant insults in wild animals (Boily et al. 2005, Novak et al. 2008, Champoux et al. 2006). However, mechanisms by which pollutants disrupt retinoid signaling were not elucidated. Vitamin A and its active metabolite RA are pivotal for embryonic growth and development, and either a deficiency or excess of RA result in congenital malformations (Lee et al. 2012). Therefore, RA is characterized as a morphogen. By binding to the RA receptors (RAR) and RXR, it controls a network of genes, particularly for homeobox genes which are critical for morphogenesis by regulating embryonic anterior-posterior patterning (Marshall et al. 1996). In addition, RXR also forms heterodimers with other receptors, including thyroid hormone receptor, 1,25-dihydroxy-vitamin $\mathrm{D}_{3}$ receptor, and PPAR (Gilardi \& Desvergne 2014). Therefore, abnormal RAR and RXR signaling could affect embryonic development.

During embryonic development, it is believed that retinol (RA precursor) is provided by maternal circulation, and that 
the fetus synthesizes its own RA, which is tightly regulated in a spatio-temporal manner, by expressing its own synthetic/catabolic enzymes, to work in concert with RAR/RXR (Tickle et al. 1982, Goldbeter et al. 2007). Requirements for RA were markedly increased at embryonic d7.5-8.5 (late gastrula stage), when Raldh2 mRNA and RA were first detected in embryonic mesoderm (Ulven et al. 2000). Tissue concentrations of RA were not homogenous in embryos; however, by creating gradients, RA acts as a signaling transduction mediator (Tickle et al. 1982, Goldbeter et al. 2007).

\subsection{RA metabolism in embryos}

Endogenous RA is synthesized from retinol in two steps. The first step involves oxidation of retinol into retinal. Many enzymes, including those in the alcohol dehydrogenase and short-chain dehydrogenase/reductase families, have this activity (Pares et al. 2008), with retinol dehydrogenase (RDH) 10 regarded as the most important enzyme during embryonic development (Ashique et al. 2012). However, this reaction can be reversed by enzymes with retinal reductase activity. One of which, dehydrogenase/reductase SDR family member 4 (DHRS4), is a peroxisomal enzyme putatively regulated by PP (Lei et al. 2003). The opposing activities of RDH and retinal reductase appear to control steady-state concentrations of retinal, the immediate precursor for RA biosynthesis (Adams et al. 2014). The second step in RA synthesis involves irreversible conversion of retinal into RA by retinal dehydrogenase (RALDH). Of the various isoforms, RALDH1, 2 and 3 (also known as ALDH1A1, 1A2 and 1A3, respectively) were reported (based on gene knockout studies) to be essential for embryonic development (Mic et al. 2002). Many cytochrome P450 enzymes exhibit RA catabolic activity (e.g., CYP1, CYP2 and CYP3) (Ross \& Zolfaghari 2011). Among them, CYP26A1, CYP26B1, CYP26C1, and CYP2C39 are the most highly expressed isoforms in the mouse liver which produce 4-oxo-, 4-OH- or 18-OH-RA for excretion (Andreola et al. 2004, Reijntjes et al. 2005, Pennimpede et al. 2010). Although Cyp26 has a highly spatiotemporally regulated expression pattern to control RA concentrations during embryogenesis (Reijntjes et al. 2005, Pennimpede et al. 2010), the importance of CYP2C39 in embryonic development is not clear. 


\subsection{Teratogenic actions of $\mathrm{PC}$}

\section{from OFO}

In 2014, we described fetal abnormalities (gross morphology and skeletal ossification) in C57BL/6J mothers exposed to oxidative deteriorated oil during pregnancy (Huang et al. 2014). There were two previous reports regarding reproductive outcomes after consumption of thermoxidized oil (Brandsch and Eder 2004, Indart et al. 2002). When female Sprague-Dawley rats were fed a diet containing $10 \%$ (by weight) oxidized oil (heated at $50^{\circ} \mathrm{C}$ for $16 \mathrm{~h}$ to reach a POV value of $754 \mathrm{meq} / \mathrm{kg}$ ), during rearing, pregnancy and lactation, the only adverse effect on reproduction was reduced birth weight (Brandsch and Eder 2004). Indart et al. (2002) reported a teratogenic potential of thermally-stressed culinary oil which was obtained by heating safflower oil at $180-220^{\circ} \mathrm{C}$ for $20 \mathrm{~min}$ to generate aldehydes (millimolar concentrations). Pregnant Wistar rats received $0.3 \mathrm{~mL}$ oil daily by gavage from day 1 of pregnancy until day 11.5, the endpoint to examine the malformations of embryos. A $22 \%$ incidence of malformations, mainly neural tube defects, was observed in the oxidized oil group compared to controls (incidence of 5-7\%). However, in contrast to our study, this teratogenic outcome was partially prevented by $\alpha$-tocopherol.

In addition to using different species, the oxidized oil we used was prepared in a way distinct from the previous two. In our study, soybean oil was heated at $205{ }^{\circ} \mathrm{C}$ in a cast iron wok, by frying wheat flour dough sheets, one at a time, for $6 \mathrm{~h} / \mathrm{d}$, repeated on four consecutive days (discontinuous heating), thus resulting in AV $1.5 \mathrm{mg} \mathrm{KOH} / \mathrm{g}$, POV $6 \mathrm{meq} / \mathrm{kg}$, conjugated diene $4500 \mathrm{OD} / \mathrm{g}$ and PC 50\%.

The OFO were separated into two fractions, namely PC and non-polar (NP) to represent oxidative altered- and non-altered components. Female C57BL/6J mice were fed a diet containing $10 \%$ dietary fat from fresh soybean oil (SO), OFO, PC and NP from conception until pregnancy day 18 , the end point to assess embryonic development (i.e. embryonic day 18). Neither OFO nor PC had significant effects on embryonic implantation, although they affected organogenesis. In contrast to no abnormalities in the SO group, the incidence of morphological and skeletal malformalities in rats fed PC were 30 and $100 \%$, and followed the order, 
$\mathrm{PC}>\mathrm{OFO}>\mathrm{NP}>\mathrm{SO}$, as residue of polar compounds retained in the NP. External malformations included visceral exposure, superficial hematoma, edema, eye and limb defects, and anencephaly. Skeletal abnormalities were mainly hypocalcification, fewer sternebrae or thoracic vertebrae. Histological examination revealed hypoplasia of retina and lung (retardation of lung branching and reduced sacculation) (Huang et al. 2014).

\subsection{Plausible mechanisms for}

\section{PC-mediated teratogenesis}

We speculated these malformations were associated with disturbed RA metabolism. For hepatic genes participating in RA metabolism, at pregnancy d18, PC increased mRNA levels of Cyp2c39 and Cyp26b1 but decreased Raldh2, Cyp26a1 and Cyp26c1 in dams, whereas increased Rdh10, Raldh1, Cyp2c39 and Cyp26a1 mRNA levels in fetuses (Huang et al. 2014). Based on these differential responses to PC in dams and fetuses, we inferred there were distinct regulatory mechanisms for RA metabolism. This is biologically plausible, since the fetus is already developing its own RA metabolic capacity at this time, and there are highly spatio-temporal controls of RA concentrations for organogenesis (Ulven et al. 2000). Regardless, the mRNA profile from a single tissue (liver) at one time-point (embryonic day 18), may not give the whole picture of PC-interfered RA signaling. To detect PC-mediated RA signaling interference, the use of transgenic RARE-Laz mice with an RA-responsive reporter transgene as biosensor and/or combined with in situ hybridization for detecting critical enzymes involved in RA metabolism is needed.

Fetal vitamin A deficiency syndrome has a spectrum of malformations including eye, ear, jaw, heart, lung, diaphragm, limb, kidney, testis and skeleton (Wilson et al. 1953). However, excess vitamin A/RA also results in malformations resembling fetal vitamin A deficiency, which was postulated to be related to long-term local RA deficiency induced by acute RA overdose (Lee et al. 2012). Based on whole embryonic RA quantification, PC-insulted fetuses had greater RA accumulation than controls at embryonic day 18 (Lin et al. manuscript in review). Although it is premature to attribute PC-induced 
teratogenesis to RA excess, since we did not characterize the entire span of pregnancy, gene expression pattern for RA synthesis (e.g. Rdh10, Dhrs4, Raldh1, and Raldh2) as well as RA catabolism (e.g. Cyp2c39, Cyp26a1, Cyp26b1 and Cyp26c1) in mothers and fetuses deviated from those of their normal counterparts implicated PC in OFO-perturbed RA metabolism (Huang et al. 2014).

As PC is a potent PPAR $\alpha$ activator and some RA metabolic genes, such as Dhrs4, Cyp2C, and Cyp26, were modulated by fibrate (a PPAR $\alpha$ agonist) (Lei et al. 2003, Fan et al. 2004, Tay et al. 2010), PC-induced teratogenesis was tested in PPAR $\alpha$ knockout mice. In the absence of functional PPAR $\alpha$, malformations, perturbation of RA metabolic gene expression as well as RA accumulation at embryonic day 18 , were detected (Lin et al. manuscript in review), suggesting PPAR $\alpha$ alone did not contribute to the PC-mediated teratogenesis and perturbed RA metabolism might have been due to a crosstalk between xenobiotic receptors, including PPAR $\alpha, \mathrm{AhR}, \mathrm{CAR}$ and PXR.

In addition to disturbed RA metabolism, PC-mediated teratogenesis might be partially attributed to DNA mutation. As suggested (Indart et al. 2002), aldehydes (formed due to lipid oxidation) are mutagenic and genotoxic, as they can covalently modify DNA to cause chromosomal aberrations, although this can be overcome by antioxidant supplementation (Indart et al. 2002).

\section{Future perspectives}

It is noteworthy that RA has been recognized as a steroid hormone, based on its role as a ligand of RAR and RXR. Thus, in addition to teratogenesis, PC might exert many physiological or pathological effects that have never been explored, through its effects on RA metabolism and the broad functions of RAR and RXR. In addition, PC might be an endocrine disrupting chemical, as many xenobiotic-induced enzymes are also involved in sex hormone metabolism (Tolson \& Wang 2010). Many environmental contaminants are known endocrine disruptors; for example, dichloro-diphenyl-trichloroethane (insecticide) (LopezCarrillo et al 1996, You et al. 1998) as well as bisphenol A (Kuiper et al. 1998, Richter et al. 2007) and di(n-butyl) phthalate (a plasticizer) (Scott et al. 2007), are well-known for 
anti-androgen or estrogenic effects. That we detected a shortened anogenital distance for pups from OFO-fed dams (unpublished results), a potential feminizing effect of OFO (or PC) on offspring should be investigated.

\section{Summary}

Proposed mechanisms for induction of teratogenesis by $\mathrm{PC}$ from $\mathrm{OFO}$ is shown (Fig 1). The PC was composed mainly of oxidized TG monomer and polymer (including dimer and oligomer) with at least one oxygenated functional group.
After being lipolized and absorbed by the intestine, these exogenous and lipophilic compounds act like xenobiotics, which can cross the placenta, and are capable of modulating transcriptional activities of xenobiotic receptors, including AhR, CAR, PXR and PPAR $\alpha$ in both mothers and fetuses. Crosstalk between these xenobiotic receptors may alter RA metabolism and signaling and perturb spatio-temporal controlled RA concentrations during organogenesis, thereby resulting in teratogenesis. 


\section{References}

Adams MK, Belvaeva OV, Wu L, et al. The retinaldehyde reductase activity of DHRS3 is reciprocally activated by retinol dehydrogenase 10 to control retinoid homeostasis. J Biol Chem. 2014; 289(21): 14868-14880.

Andreola F, Hayhurst GP, Luo G, et al. Mouse liver CYP2C39 is a novel retinoic acid 4-hydroxylase. Its down-regulation offers a molecular basis for liver retinoid accumulation and fibrosis in aryl hydrocarbon receptor-null mice. J Biol Chem. 2004; 279(5): 3434-3438.

Artman N. The chemical and biological properties of heated and oxidized fats. Adv Lipids Res. 1969; 7: 245-330.

Ashique AM, May SR, Kane MA, et al. Morphological defects in a novel Rdh10 mutant that has reduced retinoic acid biosynthesis and signaling. Genesis. 2012; 50(5): 415-423.

Bansal S, Leu AN, Gonzalez FJ, et al. Mitochondrial targeting of cytochrome P450 (CYP) 1B1 and its role in polycyclic aromatic hydrocarboninduced mitochondrial dysfunction. J Biol Chem. 2014; 289(14):
9936-9951.

Birringer M, Drogan D, Brigelius-Flohe R. Tocopherols are metabolized in HepG2 cells by side chain $\beta$-oxidation and consecutive $\omega$-oxidation. Free Radic Biol Med. 2001; 31(2): 226-232.

Boily MH, Berube VE, Spear PA, et al. Hepatic retinoids of bullfrogs in relation to agricultural pesticides. Environ Toxicol Chem. 2005; 24(5): 1099-1106.

Brandsch C, Eder K. Effects of peroxidation products in thermoxidised dietary oil in female rats during rearing, pregnancy and lactation on their reproductive performance and the antioxidative status of their offspring. Br J Nutr. 2004; 92(2): 267-275.

Champoux L, Rodrigue J, Trudeau S, et al. Contamination and biomarkers in the great blue heron, an indicator of the state of the st Lawrence river. Ecotoxicology. 2006; 15(1): 83-96.

Chao PM, Chao CY, Lin FJ, Huang CJ. Oxidized frying oil up-regulates hepatic acyl-CoA oxidase and cyptochrome P450 4A1 genes in rats and activates PPAR $\alpha$. J Nutr. 2001; 
131(12): 3166-3174.

Chao PM, Huang HL, Liao CH, et al. A high oxidized frying oil content diet is less adipogenic, but induces glucose intolerance in rodents. Br J Nutr. 2007; 98(1): 63-71.

Chen YC, Chen BH. Determination of polycyclic aromatic hydrocarbons in fumes from fried chicken legs. J Agric Food Chem. 2003; 51(14): 4162-4167.

Chiang YF, Shaw HM, Yang MF, et al. Dietary oxidized frying oil causes oxidative damage of pancreatic islets and impairment of insulin secretion, effects associated with vitamin E deficiency. Br J Nutr. 2011; 105(9): 1311-1319.

Choe E, Min DB. Chemistry of deep-fat frying oils. J Food Sci. 2007; 72(5): R77-86.

Chow CK. Biological effects of oxidized fatty acids. In: Chow CK, editor. Fatty Acids in Foods and Their Health Implications. CRC Press; 2007, 3th ed., p. $855-878$,

Cohn JS. Oxidized fat in the diet, postprandial lipaemia and cardiovascular disease. Curr Opin Lipidol. 2002; 13(1): 19-24.
Delerive P, Furman C, Teissier E, et al. Oxidized phospholipids activate PPAR $\alpha$ in a phospholipase A2dependent manner. FEBS Lett. 2000; 471(1): 34-38.

Desvergne B, Wahli W. Peroxisome proliferator-activated receptors: nuclear control of metabolism. Endocr Rev. 1999; 20(5): 649-688.

Dobarganes C, Ma'rquez-Ruiz G. Possible adverse effects of frying with vegetable oils. Br J Nutr. 2015; 113(suppl 2): S49-57.

Dobarganes MC, Ma'rquez-Ruiz G. Formation and analysis of oxidized monomeric, dimeric and higher oligomeric triglycerides. In: Erickson MD, editor. Deep frying: Chemistry, Nutrition and Practical Applications. Champaign: AOCS Press; 2007. p. 87-110.

Eder K. The effects of a dietary oxidized oil on lipid metabolism in rats. Lipids. 1999; 34: 717-725.

Ekins S, Kortagere S, Iyer $\mathrm{M}$, et al. Challenges predicting ligand-receptor interactions of promiscuous proteins: the nuclear receptor PXR. PLoS Comput Biol. 2009; 5(12): e1000594. 
Fan LQ, Brown-Borg H, Brown S, et al. PPARalpha activators down-regulate CYP2C7, a retinoic acid and testosterone hydroxylase. Toxicology. 2004; 203(1-3): 41-48.

Firestone D. Regulation of frying fat and oil. In: Erickson MD, editor. Deep frying: Chemistry, Nutrition and Practical Applications. Champaign: AOCS Press; 2007. p. 373-85.

Gao YT, Blot WJ, Zheng W, et al. Lung cancer among Chinese women. Int J Cancer. 1987; 40(5): 604-609.

Ghanayem BI, McDaniel LP, Churchwell MI, et al. Role of CYP2E1 in the epoxidation of acrylamide to glycidamide and formation of DNA and hemoglobin adducts. Toxicol Sci. 2005; 88(2): 311-318.

Gilardi F, Desvergne B. RXRs: collegial partners. Subcell Biochem. 2014; 70: 75-102.

Goldbeter A, Gonze D, Pourquié O. Sharp developmental thresholds defined through bistability by antagonistic gradients of retinoic acid and FGF signaling. Dev Dyn. 2007; 236(6): 1495-1508.

Gonz'alez-Munoz MJ, Bastida S,
S'anchez-Muniz FJ. Short term in vivo digestibility of triglyceride polymers, dimmers, and monomers of thermoxidized palm olein used in deep frying. J Agric Food Chem. 1998; 46(12): 5188-5193.

Huang CF, Lin YS, Chiang ZC, et al. Oxidized frying oil and its polar fraction fed to pregnant mice are teratogenic and alter mRNA expressions of vitamin A metabolism genes in the liver of dams and their fetuses. J Nutr Biochem. 2014; 25(5): 549-556.

Huang CJ, Cheung NS, Lu VR. Effects of deteriorated frying oil and dietary protein levels on liver microsomal enzymes in rats. J Am Oil Chem Soc. 1988; 65(11): 1796-1803.

Huang WC, Kang ZC, Li YJ, Shaw HM. Effects of oxidized frying oil on proteins related to alpha-tocopherol metabolism in rat liver. J Clin Biochem Nutr. 2009; 45(1):20-28.

Indart A, Viana M, Grootveld MC, et al. Teratogenic actions of thermally-stressed culinary oils in rats. Free Radic Res. 2002; 36(10): 1051-1058. 
Issemann I, Green S. Activation of a member of the steroid hormone receptor superfamily by peroxisome proliferators. Nature. 1990; 347(6294): 645-650.

Kanner J. Dietary advanced lipid oxidation endproducts are risk factors to human health. Mol Nutr Food Res. 2007; 51(9): 1094-1101.

Koch A, Ko“nig B, Spielmann J, et al. Thermally oxidized oil increases the expression of insulin-induced genes and inhibits activation of sterol regulatory element-binding protein-2 in rat liver. J Nutr. 2007; 137(9): 2018-2023.

Kuiper GG, Lemmen JG, Carlsson B, et al. Interaction of estrogenic chemicals and phytoestrogens with estrogen receptor beta. Endocrinology. 1998; 139 (10): $4252-4263$.

Lee LM, Leung CY, Tang WW, et al. A paradoxical teratogenic mechanism for retinoic acid. Proc Natl Acad Sci U S A. 2012; 109(34): 13668-13673.

Lei Z, Chen W, Zhang M, Napoli JL. Reduction of all-trans-retinal in the mouse liver peroxisome fraction by the short-chain dehydrogenase/reductase
RRD: induction by the PPAR alpha ligand clofibrate. Biochemistry. 2003; 42(14): 4190-4196.

Liao $\mathrm{CH}$, Shaw HM, Chao PM. Impairment of glucose metabolism in mice induced by dietary oxidized frying oil is different from that induced by conjugated linoleic acid. Nutrition. 2008; 24(7-8): 744-752.

Lin YS, Lin TY, Wu JJ, et al. Peroxisome proliferator-activated receptor $\alpha$ deficiency by itself disturbs retinoic acid metabolism but is not the main contributor to teratogenesis elicited by polar compounds from oxidized frying oil. Manuscript in review.

Liu JF, Huang CJ. Tissue $\alpha$-tocopherol retention in male rats is compromised by feeding diets containing oxidized frying oil. J Nutr. 1995; 125(12): 3071-3080.

Liu JF, Huang CJ. Dietary oxidized frying oil enhances tissue -tocopherol depletion and radioisotope tracer excretion in vitamin E-deficient rats. $\mathbf{J}$ Nutr. 1996; 126(9): 2227-2235.

LopezCarrillo L, TorresArreola L, TorresSanchez L, et al. Is DDT use a public health problem in Mexico? 
Environ Health Perspect. 1996; 104(6): 584-588.

Lu YF, Lo YC. Effect of deep frying oil given with and without dietary cholesterol on lipid metabolism in rats. Nutr Res. 1995; 15(12): 1783-1792.

Marmesat S, Rodrigues E, Velasco J, Dobarganes C. Quality of used frying fats and oils: comparison of rapid tests based on chemical and physical oil properties. Int J Food Sci Technol. 2007; 42(5): 601-608.

Ma'rquez-Ruiz G, Guevel G, Dobarganes MC. Application of chromatographic techniques to evaluate enzymatic hydrolysis of oxidized and polymeric triglycerides by pancreatic lipase 'in vitro'. J Am Oil Chem Soc. 1998; 75(2): $119-126$.

Marshall H, Morrison A, Studer M, et al. Retinoids and Hox genes. FASEB J. 1996; 10(9): 969-978.

Martin JC, Joffre FM, Siess H, et al. Cyclic fatty acid monomers from heated oil modify the activities of lipid synthesizing and oxidizing enzymes in rat liver. J Nutr. 2000; 130(6): 1524-1530.

Mic FA, Haselbeck RJ, Cuenca AE,
Duester G. Novel retinoic acid generating activities in the neural tube and heart identified by conditional rescue of Raldh2 null mutant mice. Development. 2002; 129(9): 2271-2282.

Miyagawa K, Hirai K, Takezoe R. Tocopherol and fluorescence levels in deep-frying oil and their measurement for oil assessment. J Am Oil Chem Soc. 1991; 68(3): 163-166.

Moreira RG, Castell-Perez ME, Barrufet MA. Fried product processing and characteristics. In: Deep-Fat Frying: Fundamentals and Applications. Gaithersburg, Md.: Chapman \& Hall Food Science Book. 1991:11-31.

Nagy L, Tontonoz PJ, Alvarez GA, et al. Oxidized LDL regulates macrophage gene expression through ligand activation of PPAR $\gamma$. Cell. 1998; 93(2): 229-240.

Nawar WW. Chemical changes in lipids produced by thermal processing. $\mathbf{J}$ Chem Edu. 1984; 61(4): 299-302.

Nebert DW, Russell DW. Clinical importance of the cytochromes P450. Lancet. 2002; 360(9340): 1155-1162.

Novak J, Benisek M, Hilscherova K. 
Disruption of retinoid transport, metabolism and signaling by environmental pollutants. Environ Int. 2008; 34(6): 898-913.

Pares X, Farres J, Kedishvili N, Duester G. Medium-chain and short-chain dehydrogenases/reductases in retinoid metabolism. Cell Mol Life Sci. 2008; 65(24): 3936-3949.

Parker RS, Sontag TJ, Swanson JE. Cytochrome P4503A dependent metabolism of tocopherols and inhibition by sesamin. Biochem Biophys Res Commun. 2000; 277(3): $531-534$.

Pennimpede T, Cameron DA, MacLean GA, et al. The role of CYP26 enzymes in defining appropriate retinoic acid exposure during embryogenesis. Birth Defects Res A Clin Mol Teratol. 2010; 88(10): 883-894.

Reijntjes S, Blentic A, Gale E, Maden M. The control of morphogen signalling: regulation of the synthesis and catabolism of retinoic acid in the developing embryo. Dev Biol. 2005; 285(1): 224-237.

Richter CA, Birnbaum LS, Farabollini F, et al. In vivo effects of bisphenol $\mathrm{A}$ in laboratory rodent studies. Reprod Toxicol. 2007; 24(2): 199-224.

Romero A, Bastida S, Sánchez-Muniz FJ. Cyclic fatty acid monomer formation in domestic frying of frozen foods in sunflower oil and high oleic acid sunflower oil without oil replenishment. Food Chem Toxicol. 2006; 44(10): 1674-1681.

Ross AC, Zolfaghari R. Cytochrome P450s in the regulation of cellular retinoic acid metabolism. Annu Rev Nutr. 2011; 31: $65-87$.

Saguy S, Dana D. Integrated approach to deep fat frying: engineering, nutrition, health and consumer aspects. J Food Eng. 2003; 56(2-3): 143-152.

Scott HM, Hutchison GR, Mahood IK, et al. Role of androgens in fetal testis development and dysgenesis. Endocrinology. 2007; 148(5): 2027-2036.

Shoeb M, Ansari NH, Srivastava SK, Ramana KV. 4-hydroxynonenal in the pathogenesis and progression of human diseases. Curr Med Chem. 2014; 21(2): 230-237.

Stevens JF, Maier CS. Acrolein: Sources, metabolism, and biomolecular 
interactions relevant to human health and disease. Mol Nutr Food Res. 2008; 52(1):7-25.

Sulzle A, Hirche F, Eder K. Thermally oxidized dietary fat upregulates the expression of target genes of PPAR alpha in rat liver. J Nutr. 2004; 134(6): 1375-1383.

Tang YL, Huang CJ. Dietary oxidized frying oil decreased plasma and liver vitamin A in rats. Nutr Sci J. 1998; 23: 265-279

Tareke E, Rydberg P, Karlsson P, et al. Analysis of acrylamide, a carcinogen formed in heated foodstuffs. J Agric Food Chem. 2002; 50(7): 4998-5006.

Tay S, Dickmann L, Dixit V, Isoherranen N. A comparison of the roles of peroxisome proliferator-activated receptor and retinoic acid receptor on CYP26 regulation. Mol Pharmacol. 2010; 77(2): 218-227.

Tickle C, Alberts B, Wolpert L, Lee J. Local application of retinoic acid to the limb bond mimics the action of the polarizing region. Nature. 1982; 296(5857): 564-566.

Tolson AH, Wang H. Regulation of drug-metabolizing enzymes by xenobiotic receptors: PXR and CAR. Adv Drug Deliv Rev. 2010; 62(13): 1238-1249.

Totani N, Yawata M, Takada M, Moriya M. Acrylamide content of commercial frying oil. J Oleo Sci. 2007; 56(2): 103-106.

Ulven SM, Gundersen TE, Weedon MS, et al. Identification of endogenous retinoids, enzymes, binding proteins, and receptors during early postimplantation development in mouse: important role of retinal dehydrogenase type 2 in synthesis of all-trans-retinoic acid. Dev Biol. 2000; 220(2): 379-391.

Van Wauwe JP, Coene MC, Goossens J, et al. Effects of cytochrome P-450 inhibitors on the in vivo metabolism of all-trans-retinoic acid in rats. $\mathrm{J}$ Pharmacol Exp Ther. 1990; 252(1): 365-369.

Wenzl T, Simon R, Klieiner J, Anklam E. Analytical methods for polycyclic aromatic hydrocarbons (PAHs) in food and the environment needed for new food legislation in the European Union. Trends Anal Chem. 2006; 25(7): 716-725. 
Medical Research Archives, Vol. 4, Issue 8, December 2016

Teratogenic effects of polar compounds in oxidized frying oil

Wilson JG, Roth CB, Warkany J. An analysis of the syndrome of malformations induced by maternal vitamin A deficiency. Effects of restoration of vitamin $\mathrm{A}$ at various times during gestation. Am $\mathrm{J}$ Anat. 1953; 92(2): 189-217.

Wilson R, Fernie CE, Scrimgeour CM, et al. Dietary epoxy fatty acids are absorbed in healthy women. Eur J Clin Invest. 2002; 32(2): 79-83.

Wilson R, Lyall K, Smyth L, et al. Dietary hydroxy fatty acids are absorbed in humans: implications for the measurement of oxidative stress in vivo. Free Radic Biol Med. 2002; 32(2): $162-168$.

You L, Casanova M, Archibeque-Engle S, et al. Impaired male sexual development in perinatal Sprague-Dawley and Long-Evans hooded rats exposed in utero and lactationally to p,p '-DDE. Toxicol Sci. 1998; 45(2): 162-173. 
Medical Research Archives, Vol. 4, Issue 8, December 2016

Teratogenic effects of polar compounds in oxidized frying oil

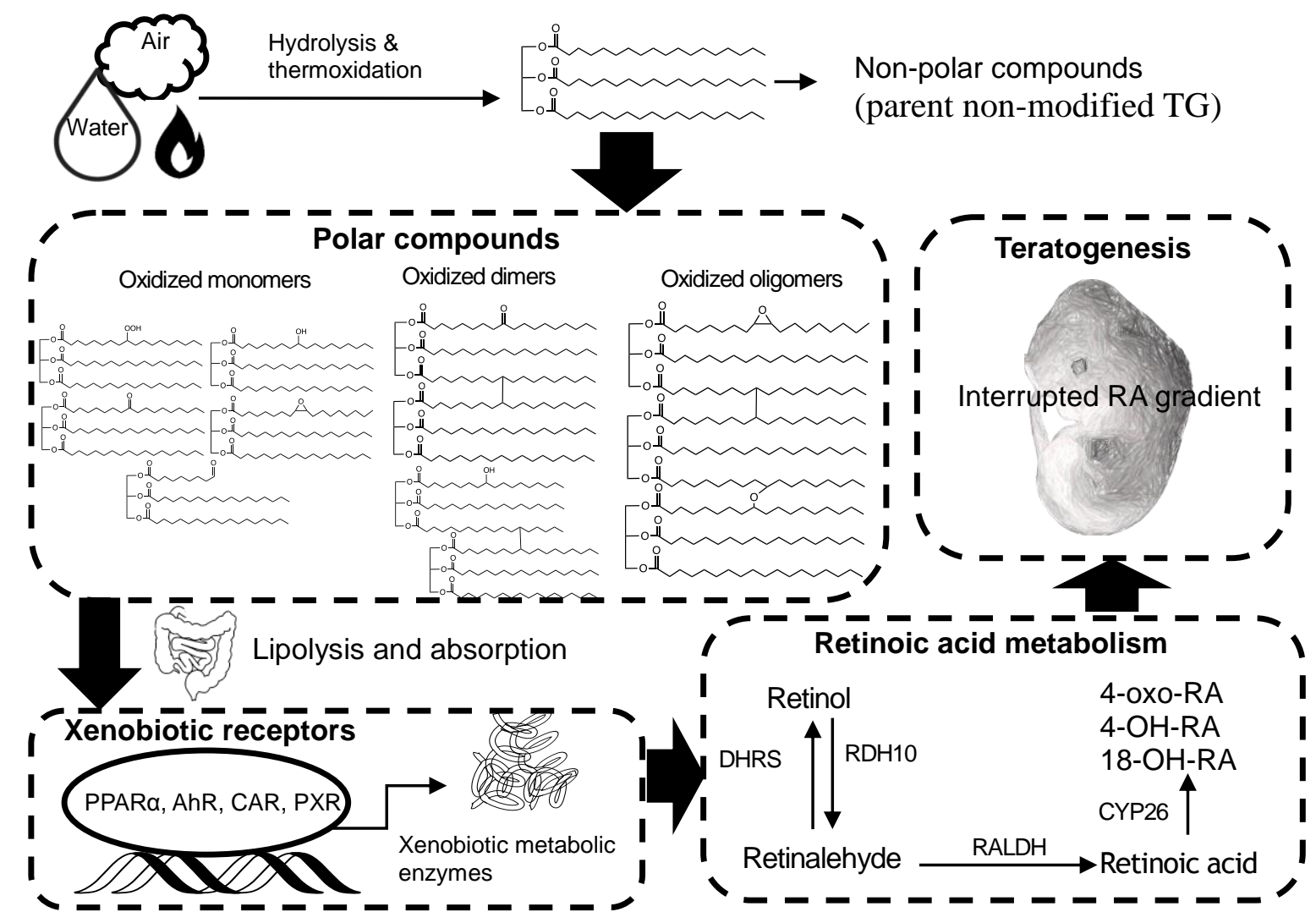

Figure 1. Proposed mechanisms for induction of teratogenesis by polar compounds. 